\title{
The dark side of biomass valorization: A laboratory experiment to understand humins formation, catalysis and green chemistry
}

\author{
Evan Pfab,§ Layla Filiciotto,§,* Rafael Luque**
}

Departamento de Quimica Organica, Universidad de Cordoba, Campus de Rabanales, Edificio Marie Curie (C-3), Ctra Nnal IV-A, Km 396, Cordoba, Spain.

sThese authors contributed equally to this work

\section{ABSTRACT}

This laboratory experiment introduces students to an important reaction in biomass valorization and allows them to gain a practical understanding of green chemistry. Acid-catalyzed dehydration reactions of fructose to 5-hydroxymethylfurfural, and thus humins, were performed both in aqueous solvent and without, along with two different catalysts (Amberlyst-15 and alumina). Students were able to compare and analyze the effects of these different conditions using Thin-Layer Chromatography, while grasping concepts of catalysis and circular economy. By observing the formation of humins under some of the reactions tested, the students could evidence systems thinking in humins valorization.

\section{GRAPHICAL ABSTRACT}

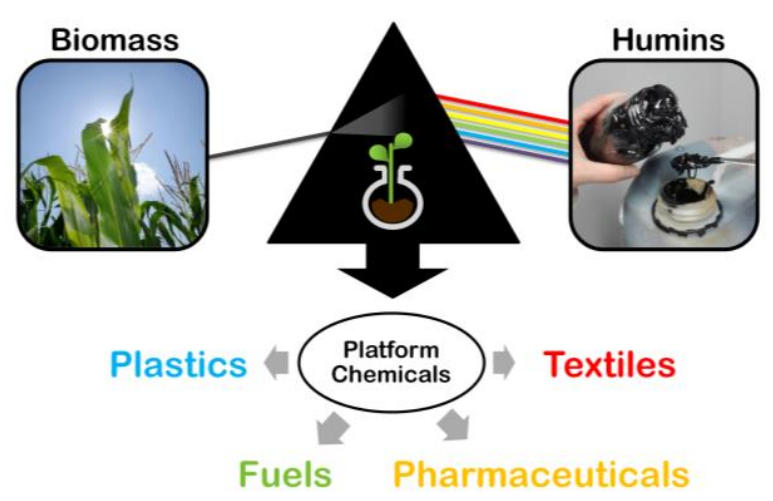

\section{KEYWORDS}

Second-Year Undergraduate, Laboratory Instruction, Interdisciplinary / Multidisciplinary, Hands-On Learning, Aqueous Solution Chemistry, Carbohydrates, Catalysis, Thin Layer Chromatography, Water / Water Chemistry, Green Chemistry, Sustainability, Systems Thinking 
There is constant pressure to shift from a petrol-based economy to a renewable and sustainable one due to climate change, ${ }^{1}$ impoverishment of traditional sources, ${ }^{2}$ overexploitation, and increased levels of pollution. ${ }^{3}$ To address this, a variety of renewable resources for energy needs (wind, solar, etc.) are currently being investigated and implemented. ${ }^{4}$ However, renewable options for the production of chemicals are more limited. While some advances have been made with $\mathrm{CO}_{2}$ (electro) conversion technologies, ${ }^{5}$ biomass valorization is currently taking hold of the scientific community. ${ }^{6}$

Biomass valorization is the process of adding value to different types of plants and residues: food crops (starch-rich) and residues (ex. rice/corn husk), aquatic plants (ex. algae), lignocellulosic plants (ex. grass), municipal waste, animal waste, and so on. ${ }^{7}$ Among all, tendencies are drawn to avoid using food crops as they are intended for human/animal use, particularly given the expected increase of the world population to +9 billion people by $2050 .{ }^{8}$ In fact, higher population density will translate into higher chemical (and energy) use as well as less available food sources (e.g. vegetables, grains). Given this trend, lignocellulosic plants are preferred for the production of plastics, pharmaceuticals and other chemicals because they contain different components that can be valorized for a variety of applications. Another advantage of lignocelluloses is their potential growth in different soils ${ }^{9}$ and their usage will increase crop diversification, thus allowing higher employment in agricultural jobs.

From a chemical point of view, these plants are made of: cellulose, a polymer of glucose (C-6 sugar); hemicellulose, a polymer of different C-5 sugars (xylose, arabinose, etc.); and lignin, an aromatic polymer which confers structural strength to the plant. ${ }^{10}, 11$ While lignin is quite challenging to convert into a selective product, ${ }^{12}$ cellulose and hemicellulose may undergo transformation, either with or without pretreatment, ${ }^{13}$ into important bio-based platform chemicals. ${ }^{14}$, 15 As an example, acid-catalyzed dehydration of bio-sugars (e.g. glucose or fructose) can yield 5-hydroxymethylfurfural (HMF) if in aqueous solution. If in alcoholic solutions (e.g., methanol), alkoxymethylfuranics like 5-methoxymethylfurfural (MMF) can be obtained. ${ }^{16}$ These furanic products may undergo further modifications into a plethora of chemical products with applications ranging from bulk (plastics, construction materials) to fine chemicals (pharmaceuticals). An example is the formation of 2,5furandicarboxylic acid (FDCA) via oxidation of HMF or MMF. In particular, FDCA polymerizes with monoethylene glycol (MEG) to form polyethylene furanoate (PEF), a 100\% bio-based plastic with 
exceptional performance properties. However, insoluble by-products known as humins (precisely, humin by-products) form in the acid-catalyzed transformation of sugars to platform chemicals (Scheme 1).
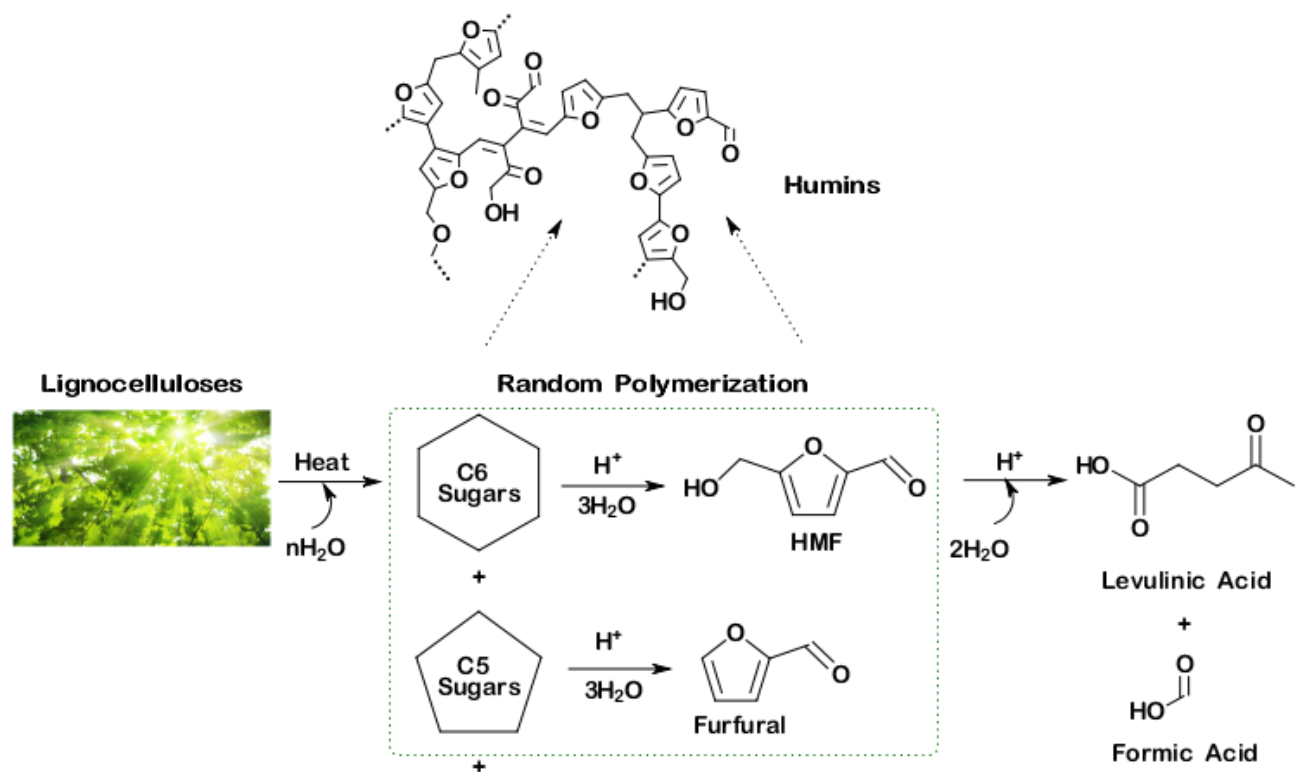

Lignin

Scheme 1. Acid-catalyzed hydrolysis of biomass to key platform chemicals and humins.

Both the structure and formation mechanism of humins are still a matter of debate, ${ }^{16}$ requiring further research. In particular, humins formation (typical yields between 10-50 wt\%) significantly reduces the efficiency and economic viability of the process, making the petrol-based processes competitive, thus still used. For this, the laboratory experience proposed herein is to display how humins are formed in a simple way, following green chemistry principles, ${ }^{17}$ so that the next generation of scientists can grow familiar with these by-products and liberate their creativity into finding new valorization routes.

Systems thinking, i.e. holistic research and learning, is advancing as a complementary approach to a reductionist view of a particular research. Recently, Orgill et al. extensively reviewed the history and key concepts of systems thinking, ${ }^{18}$ as well as the benefits associated with this comprehensive approach based on key literature examples. ${ }^{19}$ As skillfully explained, ${ }^{18}$ systems thinking can significantly contribute to improved sustainability at a global level by considering each consequence that may arise from a particular research topic. By applying a systems thinking approach to the 
formation of humins from biomass, it becomes clear that valorization routes for humins are necessary to achieve a "closed-loop" circular economy ${ }^{20}$ and improve the system's sustainability. The overall system thinking of humins valorization is given in Scheme 2. Using systems thinking, ${ }^{21}$ students are able to understand the implications that humins formation has on biomass valorization and how green chemistry can help reduce the different societal challenges mentioned above. In the experiment proposed herein, students are able to see how green chemistry strategies such as catalysis and solvent selection can help reduce the formation of humins and become familiar with an undefined product that is difficult to handle.

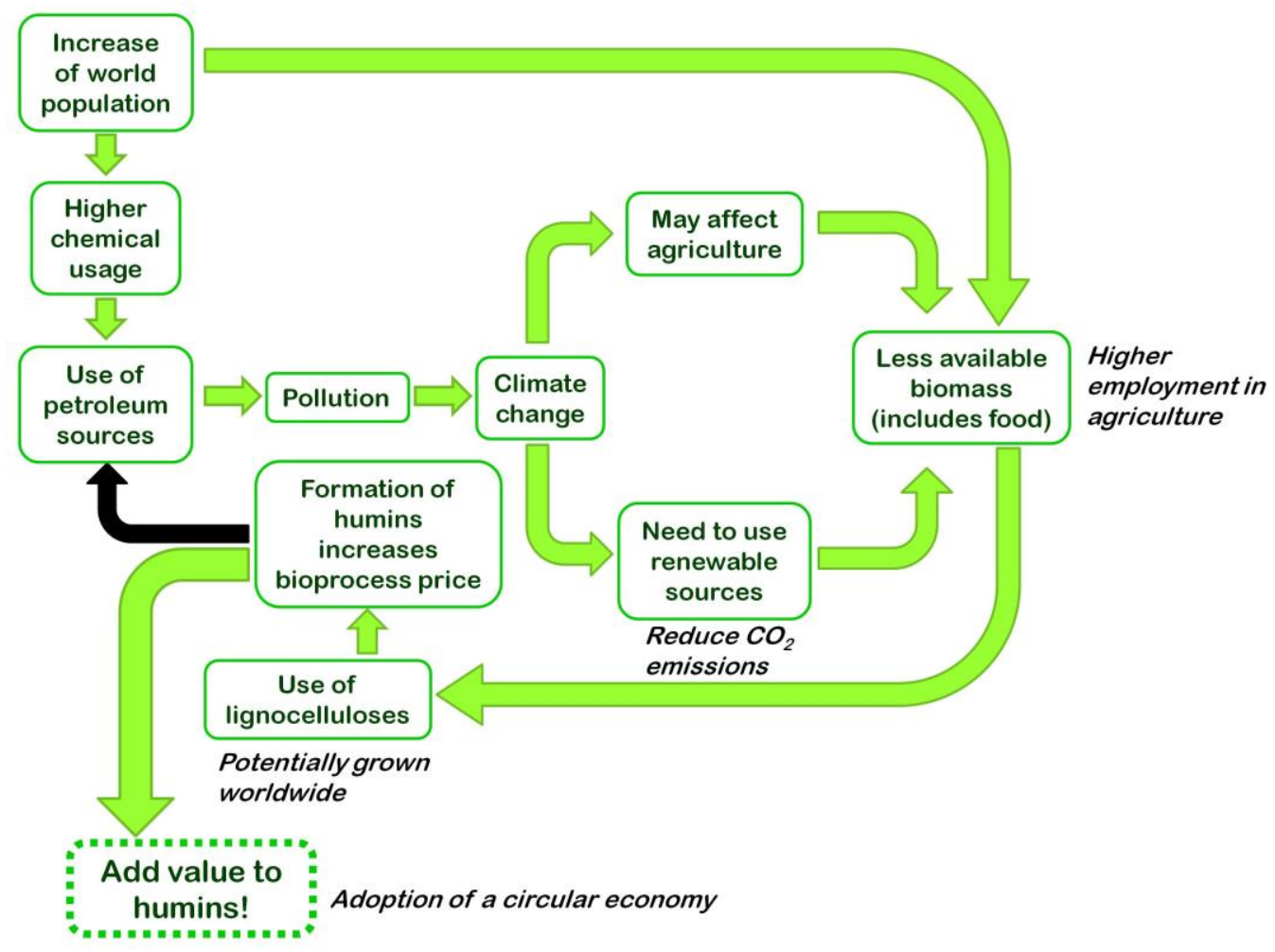

Scheme 2. Systems thinking of humins valorization.

Many examples can be found in teaching students green chemistry and waste valorization concepts. ${ }^{22-36}$ A course on green chemistry with case studies, articles, and a final project with a focus on unconventional thinking can be good for a general background on principles of sustainable chemistry. $^{23}$ This course could be coupled to different (dry) ${ }^{22}$ laboratory experiences present in literature, ${ }^{25}$ or with a full green chemistry lab activity such as that described by Sharma et al.. ${ }^{27}$ Many laboratory experiences for biomass valorization strategies can be found in literature. Some address 
material synthesis from biomass sources with green procedures (enzymatic) for the synthesis of sugarbased gelators ${ }^{28}$ or bioplastics ${ }^{29}$ from chitin/chitosan. Looking both at biofuels and materials (i.e. sunscreen), a full biomass (cellulose, hemicelluloses, lignin) valorization experiment is given by Zhou et al. ${ }^{30} \mathrm{~A}$ fermentation experiment for the production of bioethanol was also proposed. ${ }^{31}$ Even experiments for valorizing common, everyday biomass waste such as fruit peels have been proposed for adsorbent ${ }^{29}$ and shear thinning gel ${ }^{32}$ applications. A similar reaction pathway considered in this work is given by the homogeneous and heterogenous conversion of fructose to HMF with the use of a quaternary ammonium salt as the first step of HMF purification by precipitation. ${ }^{34}$ However, humins are not addressed in the work, thus overlooking the current industrial technical challenge.

The laboratory experiment outlined in this work is an opportunity for students to apply systems thinking and green chemistry principles to one of the common challenges facing a promising method for sustainability in the chemical industry. The experiment can be completed in a 3-hour lab section and is best suited for courses in advanced general chemistry or introductory organic chemistry. It would be useful to have already covered the information given in the introduction herein, and for students to be familiar with thin-layer chromatography (TLC), vacuum filtration, solvent extraction, and heating under reflux. This experiment has been performed in two different sections by separate groups of second year undergraduate students who had already completed general chemistry courses and were learning the aforementioned techniques. See the supporting information for a student handout and more details about the experiment.

\section{EXPERIMENTAL PROCEDURE}

Laboratory Experience

Students performed four acid-catalyzed dehydration reactions of fructose: three in water with different catalysts and one that is solventless. The three reactions in water were heated in an oil bath at $200{ }^{\circ} \mathrm{C}$ for 2 hours under reflux. The reflux condensers were open to atmosphere and had no external gas lines (atmospheric pressure can be assumed). The solventless reaction was performed at $100{ }^{\circ} \mathrm{C}$ for 1.5 hours with no stirring (a simple hot plate can be used) in an open vessel. It is recommended that the solventless reaction be done in a small disposable vial, as the product is very difficult to clean and can be safely disposed of. Also, it is only necessary that one solventless reaction 
be performed for each lab session. Each of the reactions in water were divided amongst pairs of students in groups of six so that two students were responsible for one of the three reactions. At the end of the experiment, the students shared their reaction observations and products amongst the group (e.g. TLC).

For each reaction, students weighed out $5.00 \mathrm{~g}$ of fructose to undergo acid-catalyzed dehydration. The three reactions in water required a magnetic stir bar, $10 \mathrm{~mL}$ of distilled water and a $100 \mathrm{~mL}$ round bottom flask. Two of these reactions are catalyzed by $100 \mathrm{mg}$ of Amberlyst-15 or Alumina and the third a blank reaction with no catalyst. When all four reactions had been prepared, $150 \mu \mathrm{L}$ of glacial acetic acid was added to each and heating under reflux was immediately started. Stirring for the reactions in water was set close to $750 \mathrm{rpm}$. After 1.5 hours, the solvent-less reaction was stopped and allowed to cool. Once cooled, $5 \mathrm{~mL}$ of acetone was added to the mixture and sonicated for 5 minutes to dissolve some of the product - only a very small portion dissolves. This resulting solution was used to spot the solvent-less reaction on a TLC plate. The three reactions in water were stopped after 2 hours and cooled in an ice bath. Once cooled, the catalysts were filtered from the two catalyzed solutions using vacuum filtration. The filtered catalysts should not be rinsed with water so that any formation of humins is visible and not washed off. The two filtered solutions and the blank were then extracted with $5 \mathrm{~mL}$ of ethyl acetate in order to spot each reaction on the TLC plate. Once all four reactions were spotted, the TLC plate was run in an eluting solvent mixture of 1:1 pentane to ethyl acetate. RF values of the obtained molecules are roughly 0.50 for $\mathrm{HMF}, 0.60$ for diformylfuran (DFF), and 0.75 for levulinic acid. If available and time permitting, students could prepare a sample of each of the reactions for GC-MS and perform a more in-depth analysis of the product formation as a follow-up during the next lab session.

Materials and lab set-up

D-(-)-fructose (>99\%), aluminum oxide-activated-weakly acidic (150 mesh) and pentane (98\%) were purchased from Sigma Aldrich. Amberlyst-15 WET was provided from Dow (Code 69286, Batch 0006759527). Glacial acetic acid (>99.5\%), ethyl acetate (99.9\%) and acetone (99.5\%) were bought from Panreac. Distilled or deionized water was used for all reactions in a solvent. 
For a complete laboratory experience, three reflux systems are required. The reflux can be carried with a round bottom flask submerged in an oil bath or in a parallel batch reactor system. For example, these experiments were first performed several times by the authors in a Carousel Reaction Station ${ }^{\mathrm{TM}}$ from Radleys Discovery Technologies to optimize reaction conditions and ensure reproducibility. Subsequently, the reactions were performed by undergraduate students who used oil baths and traditional reflux condensers. Results were found to be consistent with each setup. Furthermore, a heating plate and a disposable vial that can withstand high temperatures (at least up to $150{ }^{\circ} \mathrm{C}$ ) are required for the solventless reaction. Finally, necessary items for running TLC analyses are required (plates, beakers, cover, pipette for spotting).

All chemicals should be handled with personal protective equipment (gloves, goggles, lab-coat) and with proper ventilation (fumehood preferred, or the use of masks is required). Glacial acetic acid should be handled with extra care as it can cause skin burns and severe eye irritation. If contact is made, flush skin or eyes with water for at least 15 minutes and seek medical aid.

Ethyl acetate, acetone, pentane and glacial acetic acid are all flammable liquids that should be handled accordingly. Chemicals should be discarded as hazardous waste in appropriate bins. More safety information is provided in the supporting information.

\section{RESULTS AND DISCUSSION}

One of the biggest factors in improving the greenness of a reaction is eliminating, if possible, the use of auxiliary substances, such as solvents, or the use of a solvent with low toxicity to human and animal/plant life. Henderson et al. categorized different solvents based on physical and chemical properties such as boiling point, reactivity, and health/environmental impacts (Table 1). ${ }^{37}$ The scores in each category are broken down as the following: waste accounts for ease of handling and treatment after use (i.e. recycling, incineration, biotreatment); environmental impact accounts for solvent effects on environment; health accounts for acute and chronic effects on human health; flammability \& explosion accounts for storage and handling; and reactivity/stability accounts for factors that affect the stability of that material. The low waste value for water is surprising at first glance (especially when compared to toxic compounds such as benzene and tetrahydrofuran), but the issue with water 
based reactions lies with the final product separation. Given water's boiling point, the ability to create azeotropes (i.e. non-combustile) and the high miscibility with polar compounds, water removal and recycling can be difficult. In comparison, both benzene and tetrahydrofuran possess lower boiling points which make them easier to separate from the reaction mixtures. The lower flashpoint and autoignition temperatures of tetrahydrofuran give this solvent a lower waste score as it requires extra safety in recycling. On the other hand, non-miscibility of benzene with aqueous streams allows easy separation of this solvent easier from reaction mixtures.

Table 1. A green comparison of common industrial solvents. Adapted from GlaxoSmithKline's solvent guide. ${ }^{37}$

\begin{tabular}{|c|c|c|c|c|c|c|}
\hline Solvent & $\begin{array}{c}\text { Boiling } \\
\text { Point }\left({ }^{\circ} \mathrm{C}\right)\end{array}$ & Waste & $\begin{array}{c}\text { Environmental } \\
\text { Impact }\end{array}$ & Health & $\begin{array}{l}\text { Flammability } \\
\text { \& Explosion }\end{array}$ & $\begin{array}{c}\text { Reactivity / } \\
\text { Stability }\end{array}$ \\
\hline Benzene & 80 & 5 & 6 & 1 & 3 & 10 \\
\hline Dichloromethane & 40 & 3 & 6 & 4 & 6 & 9 \\
\hline Dimethyl carbonate & 91 & 4 & 8 & 7 & 6 & 10 \\
\hline Dimethyl sulfoxide & 189 & 5 & 5 & 7 & 9 & 2 \\
\hline Ethanol & 78 & 3 & 8 & 8 & 6 & 9 \\
\hline Ethyl acetate & 77 & 4 & 8 & 8 & 4 & 8 \\
\hline Methanol & 65 & 4 & 9 & 5 & 5 & 10 \\
\hline Tetrahydrofuran & 65 & 3 & 5 & 6 & 3 & 4 \\
\hline Water & 100 & 4 & 10 & 10 & 10 & 10 \\
\hline
\end{tabular}

For these experiments, we utilize the best auxiliaries possible: no solvent and water. The absence of a solvent reduces the distance between molecules, favoring polymerization reactions. ${ }^{38}$ On the other hand, the presence of water favors the proposed ring-opening hydrolysis of the desired bio-derived product, HMF, causing polymerization to humins. ${ }^{16}$ As the final product of our reactions is humins, these conditions are not only with the greenest solvents (or absence of), but also can give visual images of what humins look like.

Another important green chemistry concept is the use of a catalyst: by lowering the activation energies of reaction intermediates, a catalyst can overall accelerate the production of the desired chemical without being consumed in the reaction. Among all types of catalysts, homogeneous and heterogeneous catalysts are the most used in biomass conversion. 
Homogeneous and mineral catalysts, such as $\mathrm{HCl}$ and $\mathrm{H}_{2} \mathrm{SO}_{4}$ may give high conversions but low selectivity to the desired bio-derived product, HMF. ${ }^{39-41}$ Mineral acids in particular, produce high quantities of toxic materials which are difficult to dispose of. In this sense, organic acids, for example acetic or citric acid, may be used as homogeneous catalysts as they could be mineralized to $\mathrm{CO}_{2} \cdot 39,40$ In the reactions tested, a small quantity of acetic acid was used to fully drive polymerization to humins. The overall advantage of homogeneous catalysts relies on the intimate contact between the active sites (in this case, $\mathrm{H}^{+}$) and the reactant. However, these catalysts cannot be easily separated from the reaction media, greatly contributing to the waste of the reaction. ${ }^{42}$ For this reason, heterogeneous catalysts are preferred because their different state (usually solid in liquid/gas media) allows for better separation. However, the active part is only given by the superficial area of solid catalysts, thus high porosity is often looked for to improve the contact between the reactant and the active site. 43

Two catalysts were tested in this work, already seen in literature: alumina ${ }^{44}$ and Amberlyst- $15 .{ }^{45}$ Alumina as an oxide is an amphoteric material, meaning it could act as a base or as an acid. In the case of Brockmann's catalyst used in this laboratory experience, the activation of the alumina phase confers the catalyst weak acidic sites in a range of conditions, without changing the elemental composition of the material. ${ }^{46}$ On the other hand, organic or inorganic materials functionalized with active groups can act as a catalyst. This is the case of Amberlyst-15, a polymeric resin with sulfonated groups. The presence of $-\mathrm{SO}_{3}$ groups on the surface confers this polystyrene-divinylbenzene resin strong surface acidity. ${ }^{47}$

Most importantly, the difference between the two materials is the type of the surface acidity: alumina is considered a Lewis acid, while Amberlyst-15 acts as a Brønsted acid. Fructose conversion to HMF undergoes a Brønsted acid-catalyzed mechanism. Literature studies have shown Amberlyst-15 to be active ${ }^{45}$ for these reactions and alumina to be generally ineffective alone. ${ }^{44}$ The difference in activity also applies to the formation of humins. In our case, this is observed by the darkening of the reaction mixture and the catalysts. No color change is observed in any of the aqueous reactions within the first 30 minutes ( \pm 10 minutes), but a slight yellow color appeared shortly after in the Amberlyst-15 reaction and later intensified to a dark orange upon completion of the reaction. This is the first 
symptom of the formation of HMF (yellow), while the darkening shows the formation of humins (Figure 1, S1-S4). A similar trend is observed in the solventless reaction of fructose and acetic acid: upon solubilization of the sugar with heating (melting point of $103^{\circ} \mathrm{C}$ ), the mixture turned orange before turning completely black after 1.5 h (Figure S8).

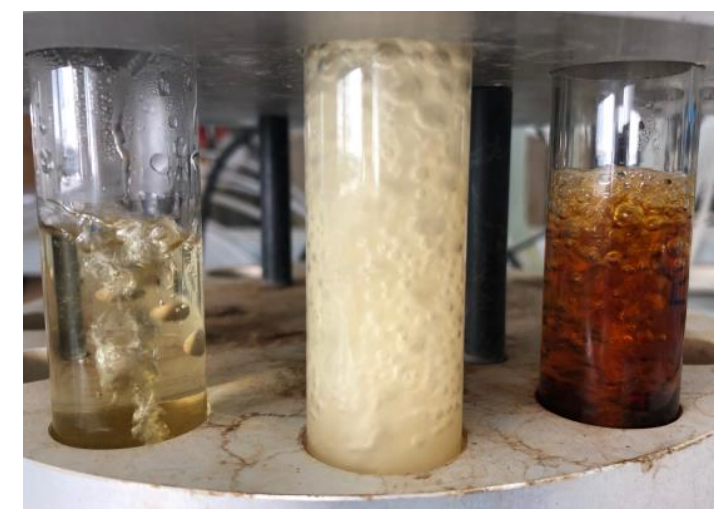

Figure 1. Reactions performed in solvent after $1.5 \mathrm{~h}$ (Left to right: blank, alumina catalyzed, Amberlyst-15 catalyzed)

The formation of humins can be observed for both of the catalyzed reactions upon filtration, and in the solventless reaction. As shown in Figure 2, Amberlyst-15 beads (originally grey) darkened to a deep brown/black and the alumina (originally white) turned a light brown/orange.

The solventless reaction yielded a sticky and viscous solution that is identified as humin byproducts (Figure 3). This is the first point for teaching the effect of a solvent and catalyst on a reaction: the former increases the physical space between reacting molecules, thus reducing the risk of polymerization; the latter, on the other hand, not only improves selectivity to a certain product, but also acts as an adsorbent due to its superficial properties. 


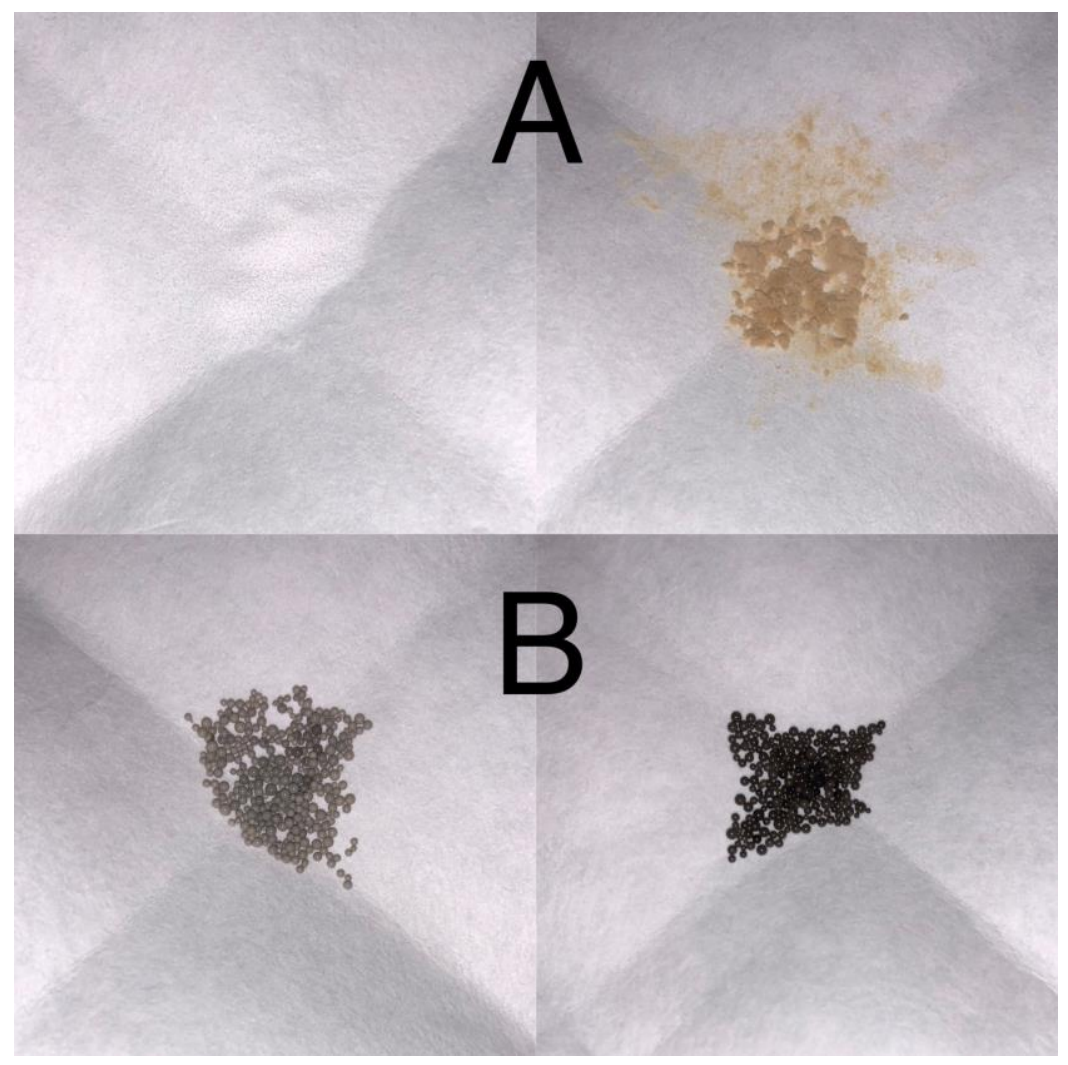

Figure 2. Alumina (A) and Amberlyst-15 (B) catalysts before and after reaction, respectively.

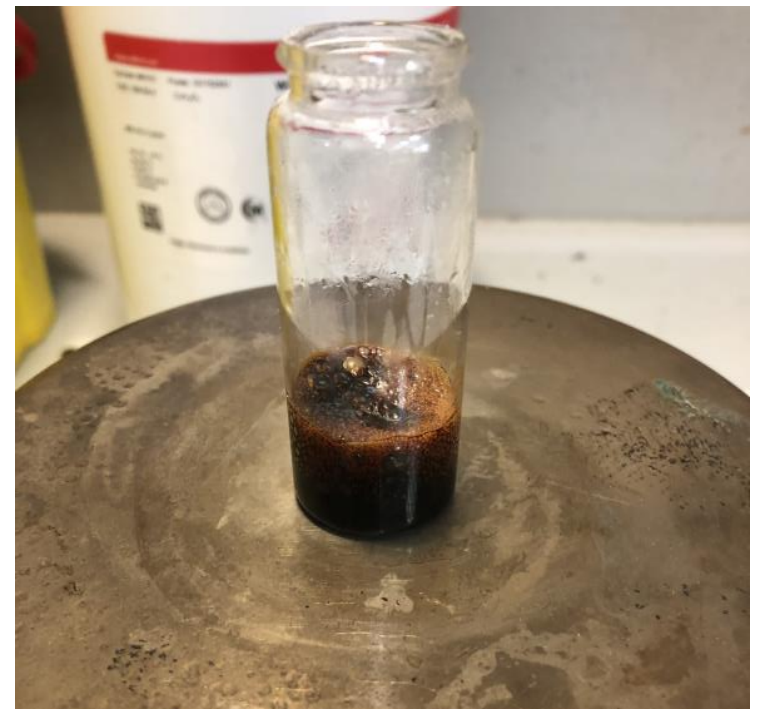

Figure 3. Humins formed in solventless conditions.

After filtration of the heterogeneous catalysts, the students performed an extraction of the aqueous phase with ethyl acetate in order to analyze the reaction results by TLC plates. Under UV light, the 
spots of Figure 4 were observed. The intensity of the TLC spots (also the color of the final solution) can give semi-quantitative information and was used as such.

In all cases, the formation of HMF is clearly observed (RF 0.5) with the strongest intensity when Amberlyst-15 (Fig. 4, C) is used. In fact, being the strongest acidic material, the highest conversion would be expected given the conditions studied in this laboratory experience. In the case of the weakly acidic alumina (Fig. 4, B), instead, lighter intensities of the products were observed, contributing to a light color of the final solution. This is a symptom of the adsorption of side-products, including humins, on the catalyst surface, as previously seen in Fig. 1. This phenomenon where a layer of carbon is deposited on the catalytic material is referred to as coking.

The formation of DFF is observed at a higher RF value (0.60). This is a result of the acid-catalyzed oxidation of HMF, a side reaction that occurs in aerobic conditions. This could be avoided by employing an inert atmosphere (e.g., $\mathrm{N}_{2}$ ). Lastly, levulinic acid is observed at $\mathrm{RF}$ value of 0.75 and is a product of the acid-catalyzed ring-opening of HMF. Levulinic acid, however, is not observed for the acetic acid-assisted reaction in water (Fig. 4, A).

The light spots give a hint of low conversion in the acetic acid-assisted reaction without a heterogeneous catalyst and in the presence of water. This could be attributed to inefficiency of the small amount of acetic acid to catalyze the dehydration for further decomposition of HMF into levulinic and formic acid. When the solventless conditions were employed, instead, unidentified peaks were observed which show the occurring of further side-reactions which decrease the atom efficiency of the process.

An overall simplified scheme of the reaction mechanism of this laboratory experience is given in Scheme 3. This reaction scheme should be taken as an example that in biomass conversion strategies, selectivity to one particular product is challenging due to the highly active oxygen containing groups that can undergo a variety of side reactions, greatly reducing process efficiency. 
Figure 4. TLC results of the four reactions. A: No heterogeneous catalyst in water; B: Alumina in water; C: Amberlyst-15 in water; D: acetic acid-assisted and solventless reaction.

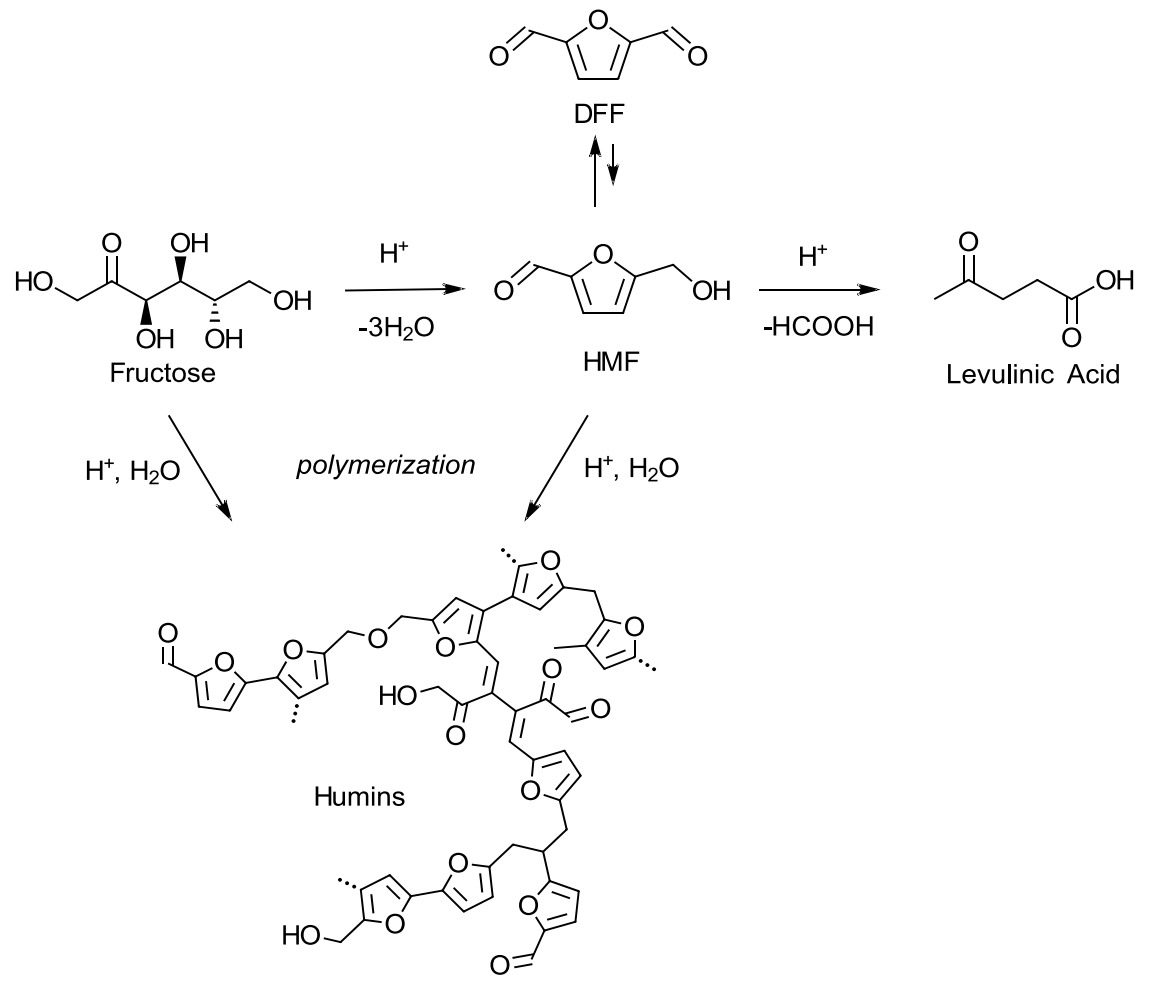

Scheme 3. Overall simplified reaction mechanism from fructose to the observed molecules. 


\section{CONCLUSIONS}

Conclusively, the students were introduced to concepts of green chemistry, systems thinking and biomass valorization with this experiment. This laboratory experiment also provided hands-on practice for common organic chemistry techniques and reactions with sugar dehydration. This should be a step into bringing the students to critically view the traditional acid-catalyzed conversion of biomass from the dark side: the formation of humins.

\section{ASSOCIATED CONTENT}

Supporting Information

The Supporting Information is available on the ACS Publications website at DOI:

10.1021/acs.jchemed.

Notes for Instructors (DOCX)

$$
\text { Students Handout (DOCX) }
$$

\section{AUTHOR INFORMATION}

Corresponding Author

*E-mail: qo2fifil@uco.es, q62alsor@uco.es

\section{ACKNOWLEDGMENTS}

E. P. acknowledges the U.S. Fulbright student program and Fulbright España for funding a research stay at Universidad de Cordoba. L. F. strongly acknowledges the European Commission for the instauration of the Marie Skłodowska Curie Actions (MSCA), and in particular their financial support as in the project HUGS (H2020-MSCA-ITN-EID-675325).

\section{REFERENCES}

1. Gao, Y.; Gao, X.; Zhang, X. The $2{ }^{\circ} \mathrm{C}$ global temperature target and the evolution of the longterm goal of addressing climate change - From the United Nations framework convention on climate change to the Paris agreement. Eng. 2017, 3(2), 272-278.

2. Kumar, V. V.; Hoadley, A.; Shastri, Y. Dynamic impact assessment of resource depletion: A case study of natural gas in New Zealand. Sustain. Prod. Cons. 2019, 18, 165-178.

3. Gray, J. S.; Bewers, J. M.; He, X. Pollution: Approaches to Pollution Control. In: Encyclopedia of Ocean Sciences, Cochran, J.K.; Bokuniewicz, H.J.; Yager, P.L. eds.; Elsevier Ltd.: New York, US, 2019, pp 366-371.

4. Cséfalvay, E.; Horváth, I. T. Sustainability Assessment of Renewable Energy in the United States, Canada, the European Union, China, and the Russian Federation. ACS Sustainable 
Chem. Eng. 2018, 6(7), 8868-8874.

5. Artz, J.; Müller, T. E.; Thenert, K.; Kleinekorte, J.; Meys, R.; Sternberg, A.; Bardow, A.; Leitner, W. Sustainable Conversion of Carbon Dioxide: An Integrated Review of Catalysis and Life Cycle Assessment. Chem. Rev. 2018, 118(2), 434-504.

6. Filiciotto, L.; Luque, R. Biomass promises: A bumpy road to a renewable economy. Curr. Green Chem. 2018, 5(1), 47-59.

7. Wu, L.; Moteki, T.; Gokhale, A. A.; Flaherty, D. W.; Toste, F. D. Production of fuels and chemicals from biomass: condensation reactions and beyond. Chem. 2016, 1, 32-58.

8. World population projected to reach 9.8 billion in 2050, and 11.2 billion in 2100 . United Nations. 2017. https://www.un.org/development/desa/en/news/population/worldpopulation-prospects-2017.html (Accessed Mar 2019).

9. Berbel, J.; Posadillo, A. Review and analysis of alternatives for the valorization of agroindustrial olive oil by-products. Sustainability 2018, 10(237), 1-9.

10. Pileidis, F. D.; Titirici, M. -M. Levulinic acid biorefineries: new challenges for efficient utilization of biomass. Bioresour. Technol. 2016, 200, 971-980.

11. Resasco, D. E.; Sitthisa, S.; Faria, J.; Prasomri, T.; Ruiz, M. P. Furfurals as chemical platform for biofuels production. Heterogen. Catal. Biomass Chem. Fuels 2011, 661, 1-33.

12. Sun, Z.; Fridich, B.; de Santi, A.; Elangovan, S.; Barta, K. Bright side of lignin depolymerization: Toward new platform chemicals. Chem. Rev. 2018, 118(2), 614-678.

13. Zhang, X.; Wilson, K.; Lee, A. F. Heterogeneously catalyzed hydrothermal processing of $\mathrm{C}_{5}-\mathrm{C}_{6}$ sugars. Chem. Rev. 2016, 116(19), 12328-12368.

14. Werpy, T. A.; Holladay, J. E.; White, J. F. Top value added chemicals from biomass: I. Results of screening for potential candidates from sugars and synthesis gas. US Department of Energy. 2011. http://www.eere.energy.gov/biomass/pdfs/35523.pdf (Accessed Mar 2019).

15. Bozell, J. J.; Petersen, G. R. Technology development for the production of biobased products from biorefinery carbohydrates - The US Department of Energy's “Top 10" revisited. Green Chem. 2010, 12, 539-554.

16. Filiciotto, L.; Balu, A. M.; van der Waal, J. C.; Luque, R. Catalytic insights into the production of biomass-derived side products methyl levulinate, furfural and humins. Catal. Today 2018, 302, 2-15.

17. Anastas, P. T.; Warner, J. C. Green chemistry: Theory and practice; Oxford University Press: New York, US, 1998; pp 1-152.

18. Orgill, M.; York, S.; MacKellar, J. Introduction to systems thinking for the chemistry education community. J. Chem. Educ. 2019, in press.

19. York, S.; Lavi, R.; Dori, Y. J.; Orgill, M. Applications of systems thinking in STEM education. J. Chem. Educ. 2019, in press. 
20. Boulding, K. E. The economics of the coming spaceship Earth. In: Environmental quality in a growing econonomy, Jarret, H. ed.; Resources for the Future/Johns Hopkins University Press: Baltimore, US, 1966; pp 3-14.

21. Matlin, S. A.; Mehta, G.; Hopf, H.; Krief, A. One-world chemistry and systems thinking. Nat. Chem. 2016, 8(5), 393-398.

22. Tamburini, F.; Kelly, T.; Weerapana, E.; Byers, J. A. Paper to plastics: An interdisciplinary summer outreach project in sustainability. J. Chem. Educ. 2014, 91(10), 1574-1579.

23. Divya, D.; Raj, K. G. From scrap to functional materials: exploring green and sustainable chemistry approach in the undergraduate laboratory. J. Chem. Educ. 2019, 96, 535.

24. Kennedy, S. A. Design of a dynamic undergraduate green chemistry course. J. Chem. Educ. 2016, 93(4), 645-649.

25. Van Arnum, S. D. An approach towards teaching green chemistry fundamentals. J. Chem. Educ. 2005, 82(11), 1689-1692.

26. Barcena, H.; Tuachi, A.; Zhang, Y. Teaching green chemistry with epoxidized soybean oil. J. Chem. Educ. 2017, 94(9), 1314-1318.

27. Sharma, R. K.; Gualati, S.; Mehta, S. Preparation of gold nanoparticles using tea: A green chemistry experiment. J. Chem. Educ. 2012, 89(10), 1316-1318.

28. Hwang, H. L.; Jadhav, S. R.; Silverman, J. R.; John, G. Sweet and sustainable: Teaching the biorefinery concept through biobased gelator synthesis. J. Chem. Educ. 2014, 91(10), 15631568.

29. Hudson, R.; Glaisher, S.; Bishop, A.; Katz, J. L. From lobster shells to plastic objects: A bioplastics activity. J. Chem. Educ. 2015, 92(11), 1882-1885.

30. Zhou, H.; Zhan, W.; Wang, L.; Guo, L.; Liu, Y. Making sustainable biofuels and sunscreen from corncobs to introduce students to integrated biorefinery concepts and techniques. $J$. Chem. Educ. 2018, 95(8), 1376-1380.

31. Epstein, J. L.; Vieria, M.; Aryal, B.; Vera, N.; Solis, M. Developing biofuel in the teaching laboratory: Ethanol from various sources. J. Chem. Educ. 2010, 87(7), 708-710.

32. Mackenzie, L. S.; Tyrrell, H.; Thomas, R.; Matharu, A. S.; Clark, J. H.; Hurst, G. A. Valorization of waste orange peel to produce shear thinning gels. J. Chem. Educ. 2019, Article ASAP. https://doi.org/10.1021/acs.jchemed.8b01009

33. Samet, C.; Valiyaveettil, S. Fruit and Vegetable Peels as Efficient Renewable Adsorbents for Removal of Pollutants from Water: A Research Experience for General Chemistry Students. J. Chem. Educ. 2018, 95 (8), 1354-1358.

34. Simeonov, S. P.; Afonso, C. A. M. Batch and flow synthesis of 5-hydroxymethylfurfural (HMF) from fructose as a bioplatform intermediate: An experiment for the organic or analytical laboratory. J. Chem. Educ. 2013, 90, 1373-1375. 
35. Goheen, D. W. Chemicals from Wood and Other Biomass. Part I: Future supply of organic chemicals. J. Chem. Educ. 1981, 58(6), 465-468.

36. Goheen, D. W. Chemicals from Wood and Other Biomass. Part II: The chemistry of conversion. J. Chem. Educ. 1981, 58(7), 544-547.

37. Henderson, R. K.; Jiménez-González, C.; Constable, D. J. C.; Alston, S. R.; Inglis, G. G. A.; Fisher, G.; Sherwood, J.; Binks, S. P.; Curzons, A. D. Expanding GSKs Solvent Selection Guide - Embedding Sustainability into Solvent Selection Starting at Medicinal Chemistry. Green Chem. 2011, 13(4), 854-862.

38. Long, T. E.; Hunt, M. O. Solvent-free polymerizations and process: Recent trends in the minimization of conventional organic solvents; ACS Symposium Series: Washington, DC, US, 1999; pp 1-5.

39. Souza, R. L. D.; Yu, H.; Rataboul, F.; Essayem, N. 5-Hydroxymethylfurfural (5-HMF) Production from Hexoses: Limits of Heterogeneous Catalysis in Hydrothermal Conditions and Potential of Concentrated Aqueous Organic Acids as Reactive Solvent System. Challenges 2012, 3(2), 212-232.

40. Asghari, F. S.; Yoshida, H. Acid-catalyzed production of 5-hydroxymethyl furfural from d-Fructose in subcritical water. Ind. Eng. Chem. Res. 2006, 45(7), 2163-2173.

41. Okano, T.; Qiao, K.; Bao, Q.; Tomida, D.; Hagiwara, H.; Yokoyama, C. Dehydration of Fructose to 5-Hydroxymethylfurfural (HMF) in an Aqueous Acetonitrile Biphasic System in the Presence of Acidic Ionic Liquids. Appl. Catal. A 2013, 451, 1-5.

42. Gürsel, I. V.; Noël, T.; Wang, Q.; Hessel, V. Separation/recycling methods for homogeneous transition metal catalysts in continuous flow. Green Chem. 2012, 17(4), 2012-2026.

43. Sudarsanam, P.; Peeters, E.; Makshina, E. V.; Parvulescu, V. I.; Sels, B. F. Advances in Porous and Nanoscale Catalysts for Viable Biomass Conversion. Chem. Soc. Rev. 2019, 48(8), 2366-2421.

44. Sampath, G.; Srinivasan, K. Remarkable Catalytic Synergism of Alumina, Metal Salt and Solvent for Conversion of Biomass Sugars to Furan Compounds. Appl. Catal. A 2017, 533, 75-80.

45. Son, P. A.; Nishimura, S.; Ebitani, K. Synthesis of Levulinic Acid from Fructose Using Amberlyst-15 as a Solid Acid Catalyst. React. Kinet. Mech. Catal. 2012, 106(1), 185-192.

46. Pines, H.; Haag, W. O. Alumina: Catalyst and Support. I. Alumina, Its Intrinsic Acidity and Catalytic Activity1. J. Am. Chem. Soc. 1960, 82(10), 2471-2483.

47. Pal, R.; Sarkar, T.; Khasnobis, S. Amberlyst-15 in Organic Synthesis. Arkivoc 2012, 2012(1), 570-609. 